\title{
AÑOS DE DISPAROS Y TORTURA (1973-1975): LOS ÚLTIMOS DÍAS DE MIGUEL ENRÍQUEZ
}

\author{
Cristián Pérez
}

Este artículo relata los últimos días de Miguel Enríquez Espinosa, líder del Movimiento de Izquierda Revolucionaria (MIR). La narración pone el acento en las estrategias utilizadas por la Dirección de Inteligencia Nacional (DINA) para dar con su paradero. A su vez, intenta despejar algunas dudas sobre el enfrentamiento de la calle Santa Fe, en Santiago, donde Enríquez fue abatido en octubre de 1974, a poco más de un año de la instauración del régimen militar que derrocó a Salvador Allende.

alle Santa Fe, comuna de San Miguel, en el sector surponiente de Santiago, sábado 5 de octubre de 1974, 13 horas. Dos vehículos, con una mujer y tres hombres a bordo, detienen su marcha en una esquina y se estacionan. La chica se queda con las camionetas, atenta, la vista en el horizonte. Tres hombres bajan; por sus gestos, forma de caminar y las armas que llevan, se percibe que son agentes de seguridad. Así es, pertenecen a los grupos Halcón I y Halcón II de la Agrupación Caupolicán de la

CRISTIÁn PÉREZ. Candidato a magíster en historia, Universidad de Santiago de Chile. 
Dirección de Inteligencia Nacional (DINA) ${ }^{1}$. Caminan lentamente observando las casas, uno se queda en la esquina, vigilante, dos se acercan a los niños que juegan en la calzada. Un chico les hace un gesto con la nariz indicándoles la casa azul-celeste signada con el $\mathrm{N}^{\circ} 725$. "Vamos a investigar", dice el jefe de impenetrables ojos azules y cabellos claros.

Los agentes se encaminan a la vivienda para verificar quiénes moran en ella. El soldado se acerca para tocar el timbre. Enseguida se arroja al suelo empujando de paso al teniente hacia el lado y al piso, cuando a través de una ventana disparan. La andanada de proyectiles calibre 7.62 pasa sobre sus cabezas. Han escapado por centímetros. El oficial se refugia tras un poste y hace fuego, el otro hombre corre a buscar un teléfono para alertar al cuartel central de la DINA.

Así comienza el enfrentamiento en que muere Miguel Enríquez Espinosa, hasta ese instante secretario general del Movimiento de Izquierda Revolucionaria (MIR) ${ }^{2}$.

Con prontitud decenas de agentes armados cercan la casa color azul-celeste $N^{\circ} 725$ de calle Santa Fe, comuna de San Miguel, en Santiago. Pasados algunos minutos, desde allí será imposible salir. Por eso, cuando aquella tarde de primavera Miguel Enríquez disparó la primera ráfaga de su fusil AKS, iniciando el enfrentamiento, quedó sellado su destino: no saldrá de ahí vivo ${ }^{3}$.

$\mathrm{Al}$ cumplirse treinta años de su muerte en aquel tiroteo, este artículo intenta reconstruir los últimos momentos del líder del MIR. El acento está puesto en los medios que permitieron a los agentes de la DINA ubicar la casa de seguridad donde él y su compañera se ocultaban.

La primera sección recoge algunos aspectos del desarrollo del MIR en la etapa de ilegalidad, que comienza en septiembre de 1973; la segunda analiza la metodología empleada por la DINA para acercarse al escondite de Miguel Enríquez; la tercera explica la forma en que los aparatos de inteligencia van ocasionándole bajas al MIR; el último acápite relata el enfrentamiento en que es abatido el jefe del movimiento.

Advertimos al lector que los nombres entre comillas simples son las chapas usadas por los militantes del MIR; aquellos nombres que aparecen entre comillas simples y cursivas han sido inventados, para proteger algunas identidades. Todas las entrevistas citadas, con los nombres reales, están en poder del autor.

${ }^{1}$ Organismo de inteligencia del régimen militar. Fue creado por decreto ley en junio de 1974.

${ }^{2}$ Organización político-militar creada en 1965.

${ }^{3}$ Luz Arce, quien era militante del Partido Socialista y luego colaboró con la DINA, afirma que en numerosas oportunidades los agentes le dijeron que a Miguel Enríquez no lo iban a capturar: simplemente lo matarían. Véase Arce, Luz: Viaje por el Infierno, 1993. 


\section{El MIR no se asila}

Hacia fines del gobierno de Eduardo Frei Montalva (1964-1970) el MIR era "[...] un pequeño grupo en la clandestinidad, con existencia orgánica en algunas provincias, con enraizamiento precario en el movimiento de masas, fundamentalmente entre algunos sectores estudiantiles y pobladores, con una corta historia, después de una división reciente (junio $1969)^{4}$ y contando con cuadros en su mayoría jóvenes y recién incorporados a la vida política"5.

El MIR debió pasar a la clandestinidad después de hacerle "un escarmiento"6 al periodista Hernán Osses Santa María en la ciudad de Concepción, y de realizar una serie de asaltos a bancos o recuperaciones, como ellos las denominaban. El Colegio de Periodistas presentó una querella contra los responsables del ataque al periodista Osses. La Corte de Apelaciones de Concepción, presidida por José Cánovas Robles ${ }^{7}$, acogió la petición y nombró ministro en visita a Héctor Roncagliolo Dosque. Éste ordenó el allanamiento del local de la Federación de Estudiantes de Concepción (FEC) y del Hogar Central, residencia de jóvenes pensionados, ambos ubicados en el barrio universitario ${ }^{8}$. También dictó órdenes de detención contra varios cabecillas de la organización. Así, con su Dirección perseguida, al grupo no le quedó más alternativa que pasar a la clandestinidad.

En esta etapa contaron con la solidaridad del entonces senador Salvador Allende ${ }^{9}$ y de soldados boinas verdes (paracaidistas y Fuerzas Espe-

${ }^{4}$ En junio de 1969, un grupo de miristas dirigidos por Rafael Ruiz ('el Rafa') se fueron del partido y crearon el Movimiento Manuel Rodríguez 2 (MR-2). El grupo tuvo corta duración, ya que fue totalmente desarticulado por la policía después del asalto frustrado a una camioneta pagadora en el supermercado Portofino. El hecho ocurrió el 25 de agosto de 1969. Fueron detenidos los estudiantes universitarios Jorge Silva Luvecce, Juan Martínez Briceño y Sergio Pérez Molina (Arancibia Clavel, Patricia y otros: Los Hechos de Violencia en Chile: Del Discurso a la Acción, 2003, p. 163).

${ }^{5}$ Comisión Política del MIR: "La Táctica del MIR en el Actual Período" [diciembre de 1973], 1998, pp. 297-298.

${ }^{6}$ La expresión entre comillas es de Andrés Pascal Allende (Secretario General del MIR entre 1974-1985). Andrés Pascal, entrevista con el autor (La Habana, agosto de 1999).

${ }^{7}$ Este ministro cobró celebridad en 1985 cuando investigó el degollamiento de tres profesionales comunistas (Parada, Nattino y Guerrero). La investigación del caso obligó a renunciar al Director General de Carabineros, César Mendoza Durán.

${ }^{8}$ Véase Avendaño, Daniel y Mauricio Palma: El Rebelde de la Burguesía. La Historia de Miguel Enríquez, 2001, pp. 92-93.

${ }^{9}$ Carmen Castillo Echeverría cuenta que para un año nuevo Salvador Allende consiguió una casa para que Miguel Enríquez, su hermano Edgardo (Pollo, 'Simón' en la clandestinidad) y Bautista van Schouwen (Bauchi), con sus respectivas parejas y niños, pasaran las fiestas en el lugar. La casa era de Miriam Contreras (Payita). Véase Echeverría, Mónica y Carmen Castillo: Santiago-París: El Vuelo de la Memoria, 2002, p. 118. 
ciales del Ejército), que los ocultaron en las instalaciones militares de Peldehue ${ }^{10}$.

Ese período terminó al poco tiempo de asumir Allende la Presidencia, cuando por la vía de los indultos y desistimientos logró liberar a quienes él llamó "jóvenes idealistas"11.

Aquella época clandestina fue, sin embargo, de poco riesgo, porque aun cuando las policías detuvieron a varios militantes y algunos de ellos denunciaron haber sufrido torturas, si éstas existieron, no fueron sistemáticas. Tres años después la situación será totalmente distinta, y de poco les servirá haber tenido esa experiencia de ilegalidad.

Durante la administración de la Unidad Popular el MIR colaboró con el dispositivo de seguridad presidencial, conocido como GAP. Max

${ }^{10}$ Testimonio de Andrés Pascal Allende (Secretario General del MIR 1974-1985). Entrevista con el autor (La Habana, agosto de 1999).

Entre los soldados destaca el oficial de Ejército Mario Melo Pradenas, quien, junto a otros militares, fue expulsado de la institución en 1970 por sustentar ideas marxistas. Posteriormente se integró al dispositivo de seguridad (GAP) del Presidente Allende. Después del golpe de Estado de 1973 fue detenido por una patrulla de la FACH. Fue visto por última vez en el campo militar de Peldehue. La última versión acerca de su muerte es que ésta ocurrió al ser arrojado desde un helicóptero para que todos los miembros de la Escuela de Paracaidistas y Fuerzas Especiales que estaban formados vieran lo que les sucedía a los traidores a la patria. Fue un escarmiento.

Sobre la participación que los ex soldados paracaidistas tuvieron en el GAP puede verse Pérez, Cristián: "Salvador Allende, Apuntes sobre su Dispositivo de Seguridad: El Grupo de Amigos Personales (GAP)", 2000.

${ }^{11}$ El 11 de noviembre de 1970, el recién inaugurado gobierno de Salvador Allende envió a los tribunales de justicia los desistimientos en los procesos por infracción a la Ley de Seguridad Interior del Estado. Algunos de los beneficiados fueron: Mauricio Cruz Díaz, Nelson Gutiérrez, Luciano Cruz Aguayo, Miguel Enríquez Espinosa, José Bordas Paz, Arturo Villabella. Véase González Pino, Miguel y Arturo Fontaine Talavera (comp.): Los Mil Días de Allende, 1997, Tomo I, p. 39.

"[...] Yo sostengo que es responsabilidad mía el haber firmado esos decretos e indultos para que compañeros jóvenes puedan incorporarse plenamente a la vida. Es cierto que algunos de ellos cometieron delitos que no pueden estimarse simplemente políticos, pero los cometieron en función de una seria convicción ideológica. Y otros países y otros pueblos, y el propio Chile, también utilizan el camino del indulto aun antes de que hubiera sentencia para obtener una pacificación amplia del país. Eso es lo que yo quiero. Y la incorporación de jóvenes idealistas dentro de la tarea constructiva de la patria tiene amplia justificación; por eso he buscado el indulto para ellos y por eso he firmado esos decretos y asumo la responsabilidad de haberlo hecho.

"De igual manera estudiamos un proyecto de amnistía que alcance a otros sectores, a quienes no llegan los decretos e indultos. Con ello queremos demostrar plenamente nuestros deseos de tranquilizar al país y dedicarlo a un esfuerzo constructivo y creador. Para este esfuerzo yo reclamo fundamentalmente la cooperación de ustedes". Allende, Salvador: "Discurso en el Congreso del Partido Socialista (La Serena, 28 de enero de 1971)", en Farías, Víctor (comp.): La Izquierda Chilena (1969-1973), 2000, Tomo I, p. 634.

La intención del Presidente era pacificar y disminuir la intensa lucha política que durante años se había desarrollado en Chile, y permitir que estos jóvenes colaboraran con el desarrollo del país. Algunos de los beneficiados pasaron a formar parte de su guardia personal (GAP). 
Marambio, un destacado militante del MIR que tenía conocimientos en esa materia, dirigió durante largo tiempo al grupo. A medida que transcurría el proceso de la Unidad Popular, las diferencias en la estrategia política entre el gobierno y el MIR se hicieron patentes. Como resultado de la disputa, el MIR fue expulsado del GAP ${ }^{12}$. En agosto de 1973 la dirección del MIR acusó a Salvador Allende de haber capitulado ${ }^{13}$.

En la mañana del martes 11 de septiembre de 1973, Miguel Enríquez se reúne en la industria Indumet con representantes socialistas y comunistas para intentar la defensa del gobierno. Allí expresa que para las cuatro de la tarde puede colocar en pie de batalla 400 hombres de su Fuerza Central, de los cuales 50 tienen módulo de combate completo. “¿Cincuenta hombres para el despliegue de una estrategia que puso en jaque a la UP?"14, ironiza Patricio Quiroga. En síntesis, el MIR no estaba en condiciones de presentar batalla contra las Fuerzas Armadas unidas, y no lo hizo.

Al atardecer de ese día (muerto Allende, controlado el país por las Fuerzas Armadas), la Comisión Política del MIR ordena el "[...] repliegue, y sólo proseguir con acciones de hostigamiento. Con una parte de nuestra dirección cercada militarmente y el resto aislado y con las comunicaciones interrumpidas; con el movimiento de masas pasivo y replegado, lo que era nuestra fuerza militar fundamental, si bien todos fuimos invadidos por la sensación de cólera e impotencia, las condiciones objetivas imponían el repliegue, y así lo hicimos con las unidades operativas y las fuerzas centrales"15. En el comienzo de una etapa de reflujo de la izquierda chilena, la dirección del MIR ordena no presentar batalla y pasar a la clandestinidad. Intentarán mantener las estructuras centralizadas (que son aquellas que dependen de la Comisión Política), el funcionamiento de los Grupos Político Militares (GPM) y enlaces con núcleos de provincias.

La intención del MIR es oponerse con todas las fuerzas posibles a la "dictadura gorila", como ellos, de acuerdo a su análisis, la denominan; en palabras de la Comisión Política, "Más bien en Chile apreciamos una dicta-

\footnotetext{
${ }^{12}$ Véase Pérez, Cristián: "Historia del MIR: 'Si Quieren Guerra, Guerra Tendrán...”, 2003.

13 "El Gobierno ha capitulado. Las masas sólo podrán confiar en sus propias fuerzas" (editorial, El Rebelde $\mathrm{N}^{\circ}$ 95, 14 de agosto de 1973). "[...] Es necesario llamar las cosas por su nombre para no seguir engañando, nunca más, a la clase obrera y al Pueblo. El Gobierno ha capitulado significativamente, y ésa es la verdad. El Gobierno no se ha fortalecido; en verdad, sólo se ha fortalecido el Estado burgués, el poder de los patrones". En Farías, Víctor (comp.): La Izquierda Chilena (1969-1973), 2000, Tomo VI, pp. 4976-4977.

${ }^{14}$ Quiroga, Patricio: Compañeros. El GAP: La Escolta de Allende, 2001, pp. 152153.

${ }^{15}$ Comisión Política del MIR: "La Táctica del MIR en el Actual Período", diciembre de 1973. En Miguel Enríquez. Con Vista a la Esperanza, 1998, p. 305.
} 
dura gorila con coro fascistoide, que intenta, no sin grandes dificultades, incorporar a los gremios empresariales y pequeñoburgueses en un Estado corporativo" 16 .

El objetivo estratégico del MIR se mantenía. Era "constituir la fuerza social que pueda iniciar una guerra revolucionaria y, a partir de ella, construir el ejército revolucionario del pueblo, capaz de derrocar a la dictadura militar, conquistar el poder para los trabajadores e instaurar un gobierno revolucionario de obreros campesinos que complete las tareas de la revolución proletaria" ${ }^{17}$. Y para el período 1973-1974 la meta táctica era "[...] fortalecer y acerar [...] el partido, constituir la fuerza social revolucionaria y dar origen al ejército revolucionario del pueblo. A partir de ello derrocar a la dictadura y conquistar el poder" ${ }^{\prime 18}$. Como vemos, el MIR mantenía las metas con las que había nacido; parecía no entender que la situación política había sufrido un brusco cambio, que en la nueva etapa la organización debía desarrollar sus actividades bajo un régimen dictatorial que controla y persigue todo asomo de disidencia, y que oponérsele podía significar tortura y muerte.

En septiembre de 1973, Miguel Enríquez vive en una casa verde olivo en la Gran Avenida José Miguel Carrera, en Santiago. Junto a él también ocupan la vivienda su compañera Carmen Castillo Echeverría (Catita, 'Jimena' en la clandestinidad), las pequeñas Camila Pascal (hija de Catita y Andrés Pascal), Javiera Enríquez Pizarro (hija de Miguel), Humberto Sotomayor (Tito, 'Tonio'), su esposa Marisa y los hijos de ambos; además, allí vive la "abuela" (madre de Humberto Sotomayor). Ésta era una militante de absoluta confianza, que en numerosas ocasiones desempeñaba el papel de empleada de la casa.

El 11 de septiembre de 1973 la Junta Militar da a conocer el Bando $\mathrm{N}^{\circ} 10$, por el que ordena, entre otras cosas, que los miembros de la Comisión Política del MIR se presenten a las 16:30 horas en el Ministerio de Defensa. Los convocados son: Miguel Enríquez, Humberto Sotomayor, Bautista van Schouwen, Andrés Pascal Allende, Nelson Gutiérrez, Edgardo Enríquez, Roberto Moreno y Arturo Villabella ${ }^{19}$. Ninguno acudió a la hora señalada, ni en los días posteriores.

Con el país totalmente controlado por las Fuerzas Armadas, la situación para los militantes del MIR era radicalmente distinta. Carmen Castillo

${ }^{16}$ Comisión Política del MIR: "La Táctica del MIR en el Actual Período" [diciembre de 1973], 1998, p. 309.

${ }^{17}$ Ibídem, p. 321.

${ }^{18}$ Ibídem, p. 321.

${ }^{19}$ Véase Avendaño, Daniel y Mauricio Palma: El Rebelde de la Burguesía: La Historia de Miguel Enríquez, p. 189. 
se ve obligada a modificar su aspecto. Para ello, desecha los jeans y la ropa que denota cierto pasado izquierdista, comienza a usar polleras, cambia el color de sus cabellos, y en adelante se comportará como una señora simpatizante de las nuevas autoridades. Por su parte, Miguel se corta los bigotes y enrula su pelo. Se "transforma" en un vendedor viajero. Con ese trabajo justifica ante el vecindario las frecuentes salidas de casa y no resulta extraño que en algunas ocasiones no llegue a dormir. La "abuela" se encarga de los quehaceres del hogar y de mantener el contacto necesario con la gente del barrio. En otras palabras, Miguel Enríquez, Carmen Castillo y las niñas se convierten en una familia normal de clase media.

La situación del secretario general es compartida por todos los militantes que tienen alguna responsabilidad en las estructuras partidarias. Deben "construir el partido y funcionar bajo estrictas medidas de seguridad y clandestinidad, cuidando siempre la compartimentación de todo, la necesidad de fachada y coartada para toda actividad, y permanentemente estar consiguiendo infraestructura para el funcionamiento propio o para eventuales perseguidos, organizar la enseñanza sistemática a todos los cuadros en las nuevas formas clandestinas de funcionamiento, entendiendo que con ello el trabajo es necesariamente más lento y difícil, pero más seguro" ${ }^{20}$. En síntesis, todos los militantes del MIR deben modificar sus hábitos de vida para trabajar eficientemente y sobrevivir en el régimen de ilegalidad que en ese momento empieza.

La vida partidaria sufre una enorme mutación: pasan de las marchas encabezadas por retratos de Che Guevara, en las que llevan cascos y coligües, y de reuniones con muchas tazas de café y cigarrillos, donde por horas debaten la coyuntura, el desarrollo estratégico del partido y la marcha global del socialismo, a citas de dos o tres miembros a bordo de un automóvil que durante horas da vueltas por calles alejadas del centro, o se juntan en algún departamento previamente conseguido para ese efecto, o bien se limitan a intercambiar informaciones por medio de enlaces o buzones.

A principios de diciembre de 1973, Miguel y su familia se mudan a la casa de color azul-celeste $\mathrm{N}^{\circ} 725$ de la calle Santa Fe, en la comuna de San Miguel. Es esta vivienda el lugar donde se produjo el enfrentamiento en que perdió la vida el secretario general del MIR.

Desde el golpe militar muchos militantes de partidos de izquierda, con y sin autorización de sus respectivas direcciones, acuden a embajadas y consulados solicitando asilo político, porque sienten amenazadas sus vidas. La jefatura del MIR, ante el desmembramiento de las organizaciones,

${ }^{20}$ Comisión Política del MIR: "La Táctica del MIR en el Actual Período" [diciembre de 1973], 1998, p. 328. 
decide que ellos no se deben asilar, pues el combate principal contra la dictadura está en el país. Así surge la consigna de guerra, que también es un desafío a los militares gobernantes: "El MIR no se asila". El grupo se queda en Chile para resistir. En sus propias palabras: "Nadie se puede restar a la lucha. Por eso, y no para sacar mezquinas ventajas partidarias frente a otros, el MIR ha sido y es contrario al asilo y o al exilio de sus dirigentes y militantes. Mi Partido ha enviado al exterior el número estrictamente necesario de cuadros para el trabajo en ese frente, y bajo la condición de regreso al país una vez cumplida su misión. Por ello los poquísimos militantes del MIR que salieron al exterior por su propia decisión sólo podrán recuperar su condición de militantes a su regreso a Chile"21.

Definitivamente, los únicos miembros del MIR eran aquellos que permanecían en Chile. Esta política se tradujo en que muchos cuadros que no contaban con la infraestructura necesaria para desempeñarse en las nuevas condiciones, corrían un riesgo alto de caer en manos de organismos de seguridad. Podía ser un precio demasiado alto.

Y lo fue, porque en la práctica significó que un segmento de los miembros con mayores responsabilidades fue apresado, asesinado y echo desaparecer ${ }^{22}$. Fue un error de apreciación de las propias condiciones que la organización tenía para enfrentar a la dictadura. Esta falla debe entenderse en el contexto de aquellos días de disparos y tortura, en que, según el MIR, lo único que no podían hacer era dejar de combatir.

Diez años después, en el Pleno del Comité Central de 1984, el grupo hizo una evaluación, señalando que "El rechazo al exilio se levantó como una política de principios. Esta política del MIR tuvo gran importancia por la fuerza moral que significó en un momento de desbande de la izquierda el que los revolucionarios se propusieran aferrarse a su pueblo y luchar junto a él [...]. Sin embargo, cometimos el error de extremar esta política y levantar a la calidad de principio una medida de manejo táctico.

${ }^{21}$ Declaraciones de Edgardo Enríquez ('Simón') (miembro de la Comisión Política del MIR) en Conferencia de Prensa, La Habana, Cuba, 26 de junio de 1974.

'Simón' era hermano de Miguel. Fue enviado por éste al exterior para encabezar el apoyo al MIR. En 1975 fue detenido en Argentina por agentes secretos de ese país. Como parte de la Operación Cóndor, habría sido enviado a Chile y entregado a la DINA. Permanece detenido y desaparecido.

Luz Arce afirma que ella vio un cable enviado desde Argentina para la DINA: "El documento provenía de un servicio de inteligencia argentino, afiliado a la agrupación Cóndor, y se le comunicaba a la DINA sobre la detención del ciudadano chileno Edgardo Enríquez Espinosa, el hermano de Miguel, a quien ponían a disposición de la DINA". Véase Arce, Luz: Viaje por el Infierno, 1993, p. 255.

${ }^{22}$ Patricio Rivas ('Gaspar'), entonces importante dirigente de la organización en Santiago, afirma que casi el $80 \%$ de los cuadros de dirección y el $10 \%$ de la militancia perecieron durante la dictadura. Patricio Rivas (miembro del Comité Central del MIR). Entrevista con el autor (Santiago, junio de 1999). 
Con el tiempo aparece como más correcto el haber implementado una táctica más selectiva: haber replegado a la retaguardia exterior una parte de la Dirección, y haber mantenido otra en Chile; haber replegado una parte de los cuadros y militantes perseguidos, manteniendo aquellos que podían vivir legalmente en el país y un núcleo de cuadros ilegales, de modo de no sobrecargar el Partido con cuadros perseguidos. La práctica demostró que el gran número de ilegales significó un enorme peso para el Partido, dificultó la clandestinidad, facilitó la acción represiva de la dictadura y la pérdida de muchos de esos cuadros que fueron encarcelados y asesinados. A pesar de nuestra política contraria al exilio, en los hechos cientos de militantes se replegaron a él por decisión propia o forzados por los hechos" $" 23$.

La implementación de esta política produjo algunas divergencias al interior de la organización, pues había miembros que abogaban porque en determinadas circunstancias los militantes del MIR pudieran asilarse. Ésta era la opinión de Víctor Toro ('Melinka'), miembro del Comité Central y fundador del $\mathrm{MIR}^{24}$.

Entonces, fue la táctica de rechazo al exilio que implementó el MIR, elevada a un rango de principios, uno de los elementos que permitieron a los hombres de la DINA dar con el refugio de Miguel Enríquez. Porque, siguiendo esta línea, se hizo imposible que el secretario general abandonara Chile y se refugiase en otro país, desde donde podía conducir al grupo. En el extranjero a la DINA se le hubiese hecho difícil atraparlo y, de haberlo conseguido, las repercusiones seguramente hubiesen sido distintas ${ }^{25}$.

\section{La Dirección de Inteligencia Nacional (DINA): A la caza de Miguel Enríquez y el MIR}

Después del golpe militar, la represión contra partidarios de la Unidad Popular fue masiva. Las Fuerzas Armadas practicaron redadas para capturar a la mayor cantidad posible de opositores ${ }^{26}$. Este procedimiento

${ }^{23}$ Movimiento de Izquierda Revolucionaria (MIR-Chile): Resoluciones Pleno Extraordinario del Comité Central, enero 1984 (sin pie de imprenta), p. 8.

${ }^{24}$ Víctor Toro ('Melinka') (miembro del Comité Central del MIR). Entrevista con el autor, Nueva York, abril, de 1999.)

${ }^{25}$ Las operaciones clandestinas de la DINA para eliminar opositores en el exterior fueron duramente criticadas por todos los sectores democráticos del orbe. Las principales operaciones fueron el asesinato del ex Comandante en Jefe del Ejército de Chile Carlos Prats González y su esposa, en Buenos Aires (30 de septiembre de 1974), el atentado contra Bernardo Leighton Guzmán y su esposa, en Roma (16 de octubre de 1975),y el asesinato de Orlando Letelier del Solar y su secretaria en Washington D. C. (21 de septiembre de 1976).

${ }^{26}$ En esa época muchas personas se aprovecharon simplemente de la coyuntura para ajustar cuentas con algún rival, acusándolo de ser partidario de la Unidad Popular y de ocultar armas o literatura subversiva en su casa. 
arcaico, descentralizado, no permitía a los militares destruir las estructuras de los partidos marxistas, ya que para cumplir ese objetivo se requería una organización que aplicara métodos de inteligencia adecuados.

En la persecución de izquierdistas se destacó desde el primer momento el comandante del Regimiento de Tejas Verdes (cerca de San Antonio), coronel de ingenieros, profesor en la Escuela de Inteligencia, Manuel Contreras Sepúlveda. Éste ganó la confianza de Augusto Pinochet cuando diseñó un organismo de inteligencia para desarticular grupos marxistas clandestinos, el cual se organizó en noviembre de 1973 como Comisión DINA y fue oficializado mediante el Decreto Ley $\mathrm{N}^{\circ} 521$, del 14 de junio de 1974. Se trataba de un organismo militar de carácter técnico profesional, dependiente directamente de la Junta de Gobierno y cuya misión consistía "en reunir toda la información en el ámbito nacional, proveniente de los diferentes campos de acción, con el propósito de producir la inteligencia que se requiera para la formulación de políticas, planificación y para la adopción de medidas que procuren el resguardo de la seguridad nacional y el desarrollo del país"27. Algunos artículos del decreto, que fueron publicados en forma reservada, le permitían allanar y detener personas sin orden judicial.

La planta estaba compuesta por miembros de las Fuerzas Armadas, carabineros y detectives, y algunos civiles.

Con recursos financieros, enorme poder y una relación estrecha de su director con el general Augusto Pinochet ${ }^{28}$, estaba en condiciones de lanzarse contra las estructuras clandestinas de la izquierda chilena, y especialmente contra Miguel Enríquez y el MIR.

En esta cruzada la DINA puso en práctica la estrategia de lucha contra organizaciones político-militares articuladas en células clandestinas o guerra antisubversiva. La estrategia había sido diseñada por expertos franceses en inteligencia a partir del conflicto de Indochina en los años 50 e implementada en la guerra de Argelia a comienzos de $1960^{29}$.

${ }^{27}$ Extracto del Decreto Supremo $\mathrm{N}^{\circ} 521$. Véase, Comisión Nacional de Verdad y Reconciliación: "Informe de la Comisión Nacional de Verdad y Reconciliación”, 1991.

${ }^{28}$ Esta estrecha relación se manifestaba en que todas las mañanas el director de la DINA concurría hasta la oficina del Presidente de la Junta Militar de Gobierno a entregarle el informe diario de inteligencia. Véase Zalaquett, Cherie: "Manuel Contreras, 'Pinochet nos Dejó Absolutamente Solos'”, 2004.

${ }^{29}$ La guerra en Argelia comenzó en 1954, cuando el Frente de Liberación Nacional argelino se levantó contra las autoridades coloniales francesas. El conflicto se extendió hasta 1962, cuando el Presidente de Francia Charles de Gaulle retiró sus fuerzas y concedió la independencia a ese país. El mejor testimonio de este conflicto es la película titulada $\mathrm{La}$ Batalla de Argel (1965), producción italiano-argelina que representa fielmente los métodos utilizados por las tropas francesas en esa lucha.

El principal ideólogo de la estrategia antisubversiva fue Roger Trinquier; y el más importante de los ejecutores, Paul Aussaresses. 
Las instrucciones para ejecutar este tipo de guerra empezaron a ser conocidas por las Fuerzas Armadas chilenas hacia fines de los años 60. Éstas provenían principalmente de los militares uruguayos, quienes habían adquirido una vasta experiencia en la lucha contra el Movimiento de Liberación Nacional-Tupamaros $(\mathrm{MLN}-\mathrm{T})^{30}$, al que combatían desde 1968. Por la forma en que se articulaban las células y el uso de tácticas de guerrilla urbana, el MIR tenía cierta semejanza con los tupamaros. También, después del golpe militar de septiembre de 1973, agentes de la DINA recibieron adiestramiento en Brasil, como lo afirma Manuel Contreras al responder a la pregunta de si conoció al general Aussaresses: "No lo conocí, pero envié muchos oficiales chilenos para que los entrenara en Manaos (Brasil). Cada dos meses le mandaba un nuevo contingente de oficiales para que los entrenara. Él trabajaba habitualmente en la sede del Servicio de Inteligencia, pero viajaba a Manaos para el entrenamiento"31. En el testimonio del director de la DINA comprobamos que oficiales de ese organismo de inteligencia viajaban hasta Brasil para ser entrenados en tácticas de lucha antisubversiva.

La estrategia creada por oficiales franceses cambió radicalmente la forma de hacer la guerra, pues el enemigo no se presenta como un ejército extranjero de ocupación, sino que son civiles de la misma nacionalidad organizados en estructuras celulares que actúan clandestinamente. Debido a eso, el teatro de guerra no está delimitado y se extiende a todas las regiones del país. Por otra parte, los militantes clandestinos no usan uniformes, ni insignias de grado, ni señas particulares, por lo que, según la concepción de guerra antisubversiva, no son combatientes reconocidos por la Convención de Ginebra ${ }^{32}$. Entonces, cuando son capturados por fuerzas

${ }^{30}$ El Movimiento de Liberación Nacional-Tupamaros (MLN-T), organización político-militar de orientación socialista, surgió en 1966. Su líder fue el abogado y asesor jurídico de los sindicatos del azúcar, Raúl Sendic. Organizados en células clandestinas que conformaban columnas independientes con sus respectivos apoyos, realizaron operaciones de pertrechamiento y propaganda armada, especialmente en las ciudades. Entre las principales acciones se cuentan el asesinato del norteamericano agente de la CIA Dan Mitrione; las dos fugas del penal de Punta Carretas, el secuestro de un diplomático inglés y la toma de la ciudad de Pando. Desde 1968 el gobierno de Jorge Pacheco Areco utiliza las Fuerzas Armadas para combatirlos, dando inicio a la guerra antisubversiva en Uruguay. La organización fue totalmente desarticulada a principios de la década de 1970. A comienzos del siglo XXI los sobrevivientes del grupo forman parte del Movimiento de Participación Popular (MPP), que forma parte del izquierdista Frente Amplio uruguayo.

${ }^{31}$ Manuel Contreras Sepúlveda, creador y jefe de la DINA. En Robin, Marie-Monique: Escuadrones de la Muerte: La Escuela Francesa, video documental (París, 2003).

${ }^{32}$ La Convención de Ginebra se realizó entre el 21 de abril y el 12 de agosto de 1949; versa sobre el "Trato de los Prisioneros de Guerra". Este convenio fue ratificado por Chile el 5 de diciembre de 1950. 
de seguridad, no se les considera como prisioneros de guerra y pueden ser asesinados o hechos desaparecer.

Para mayor claridad sobre este punto, el análisis del general (r) Manuel Contreras Sepúlveda, creador y jefe de la DINA:

[...] el concepto de prisioneros de guerra no se ajusta en absoluto a los detenidos que fueron enviados a los campamentos de detenidos en nuestro país, durante la Guerra subversiva de 1973 a 1977.

Los detenidos en Chile no cumplen con ninguna de las exigencias que se establecen para determinar que se trata de un prisionero de guerra, por cuanto:

A) No son miembros de Fuerzas Armadas de una parte contendiente.

B) Podrían ser considerados como miembros de movimientos de resistencia, pero no cumplen en absoluto con las condiciones que impone la Convención de Ginebra, para que una persona pueda ser considerada prisionero de guerra:

- No tenían jefe o Comandante que fuera una persona responsable por sus subordinados y que encabezara el Movimiento.

- Eran guerrilleros subversivos que sólo actuaban en la penumbra de la noche, en forma clandestina, atacando a mansalva y sin llevar ningún signo distintivo, por cuanto lo importante para ellos era no ser reconocidos [...].

- Sus armas solamente las llevaban ocultas y no francamente como lo exige la Convención [...].

- En ningún momento cumplieron en sus operaciones con las leyes y costumbres de la Guerra. Muy por el contrario, su acción subversiva era la de delincuentes subversivos, por cuanto también atacaron a civiles indefensos ${ }^{33}$.

El director de la DINA estima que los miristas sólo son delincuentes subversivos porque, entre otras cosas, no tenían un comandante reconocido. Por lo tanto, hacer desaparecer o torturar a militantes de ese movimiento no era un delito penalizado por las leyes de la guerra. Sin embargo, el MIR contaba con un jefe, que era Miguel Enríquez, por lo que debía considerársele una organización político-militar, y sus integrantes tenían que ser tratados de acuerdo con la Convención de Ginebra. La DINA tenía la obligación de aplicarles el estatuto de prisioneros de guerra; esto significaba que no podían ser torturados ni hechos desaparecer. Como veremos más adelante, ninguna de estas condiciones se cumplió en la persecución de Miguel Enríquez y su organización.

Uno de los aspectos fundamentales en la concepción de guerra antisubversiva es conseguir información para ubicar y aniquilar a militantes de

${ }^{33}$ Contreras Sepúlveda, Manuel: La Verdad Histórica II. ¿Desaparecidos?, 2001, p. 23. El destacado es de Manuel Contreras. 
grupos político-militares. La DINA cumplió esa tarea aplicando la tortura; también contó con la colaboración de algunos miembros que desertaron o terminaron "quebrándose" cuando fueron flagelados ${ }^{34}$.

La tortura es definida como "[...] todo acto por el cual se inflija intencionadamente a una persona dolores o sufrimientos graves, ya sean físicos o mentales, con el fin de obtener de ella o de un tercero información o una confesión, de castigarla por un acto que haya cometido, o se sospeche que ha cometido, o de intimidar o coaccionar a esa persona o a otras, o por cualquier razón basada en cualquier tipo de discriminación, cuando dichos dolores o sufrimientos sean infligidos por un funcionario público u otra persona en el ejercicio de funciones públicas, a instigación suya, o con su consentimiento o aquiescencia. No se considerarán torturas los dolores o sufrimientos que sean consecuencia únicamente de sanciones legítimas, o que sean inherentes o incidentales a éstas" 35 .

Aplicar torturas es una de las acciones más repudiadas en las sociedades modernas, principalmente porque degrada a hombres y mujeres haciéndolos perder su condición de personas. Muchas veces las secuelas de esta práctica son permanentes, es decir, no se borran con el paso del tiempo. Por este motivo se considera como un delito tan enorme que no tiene prescripción en la judicatura moderna.

En cursos de guerra antisubversiva, los instructores franceses explicaban la utilidad de la "picana eléctrica", conocida en Chile como "parrilla". Desde ese momento fue adoptada para usarla en las sesiones de tortura. Fue un método eficazmente aterrador. "[C]uando tomaban $[\ldots]$ un prisionero [...] en general lo convencían de hablar. La mayoría hablaba. Pero al que no quería [hacerlo], lo sometían a sufrimientos físicos, sufrimientos mortales que hacían que terminara por hablar [...], si otro prisionero asistía a la sesión de tortura se convencía de hablar porque sabía que sería el siguiente" ${ }^{36}$. En síntesis, era prácticamente imposible, y por lo demás suicida, resistir la tortura.

${ }^{34}$ Las más reconocidas colaboradoras de la DINA fueron Marcia Merino ('Flaca Alejandra') y Luz Arce. Ellas fueron "quebradas" en la tortura, y posteriormente se desempeñaron como agentes de ese organismo.

${ }^{35}$ Oficina del Alto Comisionado para los Derechos Humanos, "Convención contra la Tortura y otros Tratos o Penas Crueles, Inhumanas o Degradantes". Adoptada y abierta a la firma, ratificación y adhesión por la Asamblea General en su resolución 39/46, 10 de diciembre de 1984. Entrada en vigor: 26 de junio de 1987, de conformidad con el artículo 27. Véase, http:www. Unhchr.ch/spanish/html/menu3/b/h_cat39_sp.htm

${ }^{36}$ Relato del coronel Carl Bernard, alumno de Paul Aussaresses en Fort Bragg (base de las tropas especiales de Estados Unidos), en Robin, Marie-Monique: "Escuadrones de la Muerte. La Escuela Francesa”, video documental (París, 2003). 
Junto con la aplicación concreta de la "parrilla", crearon un dispositivo que podríamos llamar de disuasión o miedo. Se trataba de comunicar a los miristas el trato que recibirían si eran detenidos. Esto creó una sicosis respecto de los efectos y las posibilidades de resistir la flagelación ${ }^{37}$. El hecho de saber que en cuarteles secretos podían ser torturados, quizás hasta la muerte, hizo que algunos hablaran antes de pasar por esa práctica.

A los militantes del MIR apresados por la DINA en aquellos días de disparos y tortura les colocan una capucha que les impide ver, luego los trasladan hasta una cárcel clandestina ${ }^{38}$. Allí, desde el primer momento son sometidos a un régimen de vida infrahumano: reciben golpizas de pies y puños, les alteran las horas de sueño o no los dejan dormir para que pierdan la noción del tiempo, les impiden acudir al baño y comer, algunos son violados repetidas veces hasta por perros especialmente entrenados, después son llevados a la "parrilla", que no es otra cosa que la aplicación de golpes de electricidad en las partes más sensibles del cuerpo; este tratamiento es acompañado con largos y agotadores interrogatorios, durante los cuales les preguntan por sus actividades y posición en la estructura del grupo, sobre el nombre o chapa de sus compañeros, acerca de la ubicación de sus casas y depósitos de armas, y por el refugio de Miguel Enríquez y otros líderes.

La dirección del MIR estaba convencida de que se podía resistir la tortura, por eso daba instrucciones precisas de que si un militante era flagelado y entregaba información que permitiera la captura de otros miembros de la organización, o se convertía en una colaborador, "[...] su nombre [sería] entregado a todos los militantes, al resto de la izquierda y a movimientos revolucionarios del mundo. [Y advertían que] se reservarán el derecho de aplicarle las más duras sanciones y medidas, cuyo tenor será acorde con el grado de desarrollo de la lucha"39.

Según el general francés (r) Paul Aussaresses, el más importante de los difusores de la guerra antisubversiva, en Chile, bajo el gobierno de Pinochet, se aplicaron los mismos métodos que en la guerra de Argelia ${ }^{40}$.

${ }^{37}$ Lo mismo hicieron los encargados de la Escuela de Mecánica de la Armada, principal centro de detención para miembros de Montoneros en Argentina. Entrevista a 'Sergio Berrios', ex agente de la marina argentina (Buenos Aires, abril de 2004.)

${ }^{38}$ Los recintos de detención más importantes que utilizó la DINA fueron: José Domingo Cañas (Cuartel Ollagüe), Londres 38, Villa Grimaldi, La Venda Sexi. Para un relato detallado de estos centros, véase Tamayo, Tania y Claudia Lagos: "Arquitectura del Espanto: Casas de Tortura y Centros de Detención", 2003.

${ }^{39}$ Comisión Política del MIR: "A Fortalecer Nuestro Partido" [Santiago, 16 de junio de 1974], 1998, p. 338.

${ }^{40}$ Véase Iglesias, Juan Pablo: "Paul Aussaresses: 'En Chile se Aplicaron los Mismos Métodos que en la Guerra de Argelia”, 2003. 
Con estos antecedentes queda claro que los dispositivos que utilizó la DINA en la persecución de Miguel Enríquez y su organización fueron aquellos diseñados por la inteligencia francesa para combatir a grupos articulados en células clandestinas o guerra antisubversiva.

Mediante este método los agentes de la DINA fueron reconstruyendo en sus archivos la estructura del MIR. Lenta pero en forma segura, en la medida en que iban cayendo militantes del grupo, la DINA se acercaba a Miguel Enríquez. Así, con los miembros del MIR en la mira de cientos de agentes de seguridad, la hora final estaba cerca.

\section{Las primeras bajas en el MIR}

Inmediatamente después del golpe militar de septiembre de 1973, el MIR sufrió perdidas en sus niveles medios; la más significativa fue la caída de la Dirección Regional de Valdivia. En esta ciudad, el 3 y 4 de octubre, un consejo de guerra condenó a muerte a 12 personas. Entre los fusilados se encontraban Fernando Krauss Iturra, secretario regional, y José Gregorio Liendo Vera ('Comandante Pepe'), líder del Movimiento de Campesinos Revolucionarios $(\mathrm{MCR})^{41}$.

Pero el primer golpe importante que le dan al MIR ocurre el 13 de diciembre de 1973. Ese día, desde una iglesia en el centro de Santiago donde se encuentran refugiados, son apresados Bautista van Schouwen (Bauchi), miembro de la Comisión Política y director de El Rebelde ${ }^{42}$, y Patricio Munita ('James'), su guardaespaldas ${ }^{43}$.

La dirección del MIR sabe del arresto pero no conoce el lugar en que Bauchi y 'James' se encuentran cautivos. El MIR ignoraba que luego de sufrir atroces torturas, ambos fueron asesinados al día siguiente de su detención (14 de diciembre). Por eso la dirección del MIR decía, "rendimos nuestro emocionado homenaje [...] al compañero Bautista van Schouwen Vasey, médico, 30 años, un hijo, miembro de la Comisión Política del MIR; vivo o muerto, héroe de la Resistencia chilena. Resistió la tortura de cuatro

${ }^{41}$ Véase Comisión Nacional de Verdad y Reconciliación: "Informe de la Comisión Nacional de Verdad y Reconciliación”, 1991.

El Movimiento de Campesinos Revolucionarios (MCR) era la organización campesino-mapuche del MIR. Su líder fue Moisés Huentelaf y a su muerte en el enfrentamiento del fundo Chesque quedó en manos de José Gregorio Liendo ('Comandante Pepe').

${ }^{42}$ El Rebelde era el periódico del MIR. Nunca dejó de imprimirse, aun en las peores épocas del movimiento. En alguna oportunidad, cuando el grupo no contaba con imprenta, salió manuscrito y fotocopiado.

${ }^{43}$ Guzmán, Nancy: Un Grito desde el Silencio. Detención, Asesinato y Desaparición de Bautista van Schouwen y Patricio Munita, 1998. 
servicios de inteligencia del gorilaje chileno que se ensañaron con él, lo despedazaron con torturas salvajes, a pesar de lo cual este camarada se limitó a decir su nombre e insultar a los torturadores [...]. Tres veces fue llevado en estado de coma al Hospital Militar y aun así no se dejó quebrantar por la tortura. Hasta ahora Pinochet y sus esbirros se han negado a reconocer que lo tienen detenido o que ya lo asesinaron [...]. Pero si existe una posibilidad de que Van Schouwen esté vivo, llamamos a toda la opinión pública mundial $[\ldots]$ a redoblar su denuncia de esta situación para evitar que el camarada Van Schouwen sea fusilado o siga siendo sometido a torturas atroces. Y si ya lo fusilaron, llamamos a todo el mundo a exigir a la Junta Militar que muestre su cadáver y reconozca su asesinato en las cámaras de tortura del régimen" 44 .

Nancy Guzmán sostiene que Miguel Enríquez, con el fin de obligar a la dictadura a entregar el paradero de Bauchi para luego intentar una operación de rescate con sus fuerzas especiales y, al mismo tiempo, levantar la moral de los militantes, realiza una maniobra de inteligencia. En efecto, envía información falsa sobre el paradero de Bauchi al extranjero para que rebote en las agencias cablegráficas y vuelva nuevamente a Chile ${ }^{45}$.

Asimismo, publica una foto trucada donde Van Schouwen aparece vivo, pero en malas condiciones físicas, en un hospital. Esta maniobra resultó altamente creíble para militantes de izquierda. Así, por ejemplo, Javier de la Fuente, miembro del Partido Socialista de Valparaíso, en ese tiempo también en la clandestinidad, estaba convencido de que Bauchi había desaparecido desde el Hospital Naval de Valparaíso, porque había visto aquella foto ${ }^{46}$.

También Miguel Enríquez, usando como ejemplo a Van Schouwen, edita un documento que muestra el comportamiento que él espera deben tener los militantes del MIR al enfrentar interrogatorios y torturas. El secretario general afirma que Bauchi " [...] fue torturado sanguinariamente durante semanas y meses sin hablar nada, respondiendo a las torturas, como atestiguan compañeros que estaban siendo torturados en celdas contiguas, con insultos a los torturadores y con gritos de certeza en la victoria de la

${ }^{44}$ Declaraciones de Edgardo Enríquez ('Simón') en “Conferencia de Prensa de Edgardo Enríquez”, 1974.

${ }^{45}$ Véase, Guzmán, Nancy: Un Grito desde el Silencio. Detención, Asesinato y Desaparición de Bautista van Schouwen y Patricio Munita, 1998.

${ }^{46}$ Javier de la Fuente (dirigente del Partido Socialista). Entrevista con el autor (Putaendo, Chile, marzo de 1999). 
revolución obrera y campesina, y aún no sabemos con seguridad si está vivo o muerto" 47 .

Compartimos la idea de Nancy Guzmán en el sentido de que la intención de Miguel Enríquez era lograr que los servicios de seguridad dieran a conocer el lugar donde Bauchi estaba detenido, para luego intentar su rescate. Y agregamos que es posible que agentes de la Comisión DINA no consiguieron que les dijera el paradero de Miguel, y ante el temor por un intento de rescate, lo asesinaron y ocultaron el hecho.

Pese a esta enorme pérdida, hacia marzo de 1974 Miguel Enríquez había materializado la reestructuración del MIR en todos los niveles (desde la Comisión Política hasta los núcleos provinciales). En Santiago el proceso estaba más acelerado y era un poco más lento en regiones.

A fines de ese mes sufren las primeras caídas en serie. Éstas fueron provocadas por el Servicio de Inteligencia de la Fuerza Aérea de Chile (SIFA). El 27 de marzo son detenidos un miembro de la Comisión Política y otro del Comité Central ${ }^{48}$. El 29 caen otros integrantes. Desde allí la espiral ya no se detiene. A mediados de abril la SIFA captura a Víctor Toro ('Melinka') $)^{49}$.

Durante meses la SIFA mantiene cautivos a estos militantes en la Academia de Guerra Aérea (AGA). En ese lugar sufren torturas y tratos crueles $^{50}$.

Con varios miembros de la Comisión Política y del Comité Central detenidos, la SIFA estimó que estaban dadas las condiciones para realizar una negociación con el MIR. Ésta "consistía en canjear a los presos que había en ese momento en el AGA a cambio de que el MIR entregara las armas. El puente de esta conversación se hizo a través de Laura Allende (hermana de Salvador Allende) y monseñor Carlos Camus"51. Pretendían terminar con la resistencia del grupo y ganar "el gallito" a sus rivales de la DINA. En otras palabras, la pugna DINA-SIFA correspondía, en el campo de la inteligencia, a la pugna por el poder entre Augusto Pinochet y Gustavo

${ }^{47}$ Comisión Política del MIR: "A Fortalecer Nuestro Partido" [Santiago, 16 de junio de 1974], 1998, p. 337.

${ }^{48}$ Uno de los capturados era Arturo Villabella, ingeniero, miembro de la Comisión Política y responsable de las estructuras militares del movimiento. Al resistirse a la detención recibió siete impactos de bala.

${ }^{49}$ Otros detenidos importantes eran: Roberto Moreno ('Pelado'), miembro de la Comisión Política, encargado de la reorganización del MIR en las provincias; Luis Retamal ('Reta') y Patricio Rivas ('Gaspar').

${ }^{50}$ Declaraciones de Víctor Toro (miembro del Comité Central del MIR). Entrevista con el autor (Nueva York, abril, 1999).

${ }^{51}$ El relato es del militante del MIR Leonardo Schneider ('El Barba'), quien fue colaborador del Servicio de Inteligencia de la Fuerza Aérea (SIFA). En Camus, María Eugenia: "Las Confesiones de Schneider, 'El Barba”, 2002. 
Leigh $^{52}$. La iniciativa no prosperó por la oposición de Miguel Enríquez y de los miembros del MIR detenidos en la AGA, entre ellos Arturo Villabella, Roberto Moreno y otros. Pero la confirmación de quiénes eran los que estaban presos en ese lugar y el tenor de las negociaciones en que participaron Laura Allende y el obispo de Linares hicieron posible que tiempo después los detenidos pudieran abandonar el país. Quizás fue ésta la última oportunidad que tuvo Miguel Enríquez de conservar su vida. Sin embargo, la sola idea de capitular, aunque fuera transitoriamente, era impensable para él.

$\mathrm{Al}$ tenor de estos acontecimientos, la lucha entre servicios de inteligencia por destruir al MIR se intensificaba, como se advierte en el hecho que la DINA haya secuestrado al 'El Barba' Schneider, un ex mirista que trabajaba para la SIFA.

A mediados de 1974 los partidos Socialista y Comunista, muy golpeados por la represión, apenas sobrevivían; carecían totalmente de capacidad para articular expresiones públicas de disidencia. En ese marco el único problema que tenía el gobierno para consolidar su política de pacificación nacional era la oposición que hacía el MIR, aunque ésta fuera más verbal que práctica. Entonces, para las fuerzas de seguridad el objetivo era nítido: debían destruir al MIR, y la mejor forma de hacerlo era capturar o asesinar a Miguel Enríquez. ¿Quién lo hará, la DINA o la SIFA?

\section{La hora final ${ }^{53}$}

Fueron agentes de la DINA quienes propinaron golpes demoledores a las principales estructuras del MIR. Es en la primavera de 1974 cuando comienza a estrecharse el cerco que acabó con la vida del secretario general del MIR.

El 21 de septiembre de 1974, el "guatón" Romo, Troglo y "Flaca Alejandra' (antigua militante del MIR que colabora con la DINA) salen a "porotear" ${ }^{54}$ las calles de Santiago en busca de algún mirista. De casuali-

${ }^{52}$ En Kustcher Wach, Annie: "Los Contactos del MIR con la Fuerza Aérea”, 1999.

${ }^{53}$ En esta sección nos basamos principalmente en las siguientes fuentes: Carmen Castillo E.: Un Día de Octubre en Santiago, 1987; Carvallo, Mauricio: "Miguel Krassnoff Martchenko: 'Comparto el 'nunca más' de Cheyre"; "En Enfrentamiento con la Policía Muere el Prófugo Miguel Enríquez" (crónica), diario La Tercera (domingo 6 de octubre de 1974); "El MIR Trasladó su Directiva a París", (cable AP), La Segunda, 7 de octubre de 1974, p. 15; Avendaño, Daniel y Mauricio Palma: El Rebelde de la Burguesía: la Historia de Miguel Enríquez, 2001; y las entrevistas ya citadas a Roberto Moreno, Patricio Rivas y Andrés Pascal Allende.

54 "Porotear" era una acción que realizaba la DINA. Consistía en sacar a un militante a recorrer las calles con el fin de encontrar a algún miembro del MIR. 
dad encuentran a Lumi Videla (la "Negra", 'Luisa'), antigua dirigente del Pedagógico, compañera de Sergio Pérez ('Chico'). De inmediato se le echan encima y la capturan. Sergio y Lumi eran responsables del sector Organización, encargados de mantener enlaces con las estructuras regionales.

Durante largo tiempo la "Negra" es interrogada bajo atroces torturas, pero se niega a entregar el lugar donde vive, esperando que sean las 10 de la noche, hora en que su compañero debe dejar la casa en virtud del acuerdo que tienen ${ }^{55}$. Así lo hace Sergio Pérez, lleva consigo documentos donde aparecen citas con sus enlaces y un depósito con algunas armas. Inexplicablemente, en la madrugada del día siguiente, convence a 'Tonio' para que lo acompañe y retorna a la casa, sin saber que ésta ya ha sido entregada por Lumi Videla. En el lugar la DINA ha dejado algunos agentes por si alguien llega. El 'Chico' porta un revolver calibre 38 y una granada de mano. Entra a la casa, inmediatamente le dan un tiro en una pierna y lo capturan. 'Tonio', al oír el disparo, en lugar de intentar el rescate de su compañero, abandona el lugar y parte a dar cuenta a Miguel Enríquez. A continuación éste y 'Tonio' se acercan a la casa donde ha caído el 'Chico' para intentar quitárselo a la DINA. No consiguen su objetivo porque ya la zona se encuentra controlada por fuerzas de seguridad.

Sergio Pérez y Lumi Videla ('Luisa') ${ }^{56}$ murieron a raíz de las torturas sin entregar el paradero de Miguel, quizás tampoco lo conocían. Es posible que la "Negra" intentara negociar con la DINA; tal vez trató de hacerles creer que colaboraba con ellos para ganar tiempo y mantenerse con vida, y cuando los agentes descubrieron el engaño la torturaron hasta la muerte. Ésta es la versión de Luz Arce, quien compartió con ella esos días en el centro de detención, José Domingo Cañas ${ }^{57}$.

Poco después de la caída de Sergio Pérez, Miguel se reúne con enlaces de éste para tomar medidas que eviten la desconexión con las provincias, que podía conducirlos al desastre total, y les pide que abandonen la casa donde viven porque 'Chico' la conoce; ellos se niegan y deciden permanecer allí, seguros de que 'Chico' nunca entregará ese lugar. Error.

${ }^{55}$ Ellos están de acuerdo en que si alguno no llega antes de las 10 de la noche sin explicar la tardanza, significa que ha sido atrapado por la DINA. Era un pacto para protegerse mutuamente.

${ }^{56}$ En los primeros días de noviembre de ese año su cadáver fue tirado en el patio de la embajada de Italia en Santiago, con un cartel que decía "Sólo así se pueden asilar los militantes del MIR". La prensa gobiernista habló de una orgía mirista al interior de la sede diplomática, versión que fue desmentida por las autoridades italianas.

${ }^{57}$ Arce, Luz: Viaje por el Infierno, 1993. 
En la madrugada un grupo de agentes llega a la casa donde vivían los enlaces y detiene a tres personas, además encuentran papeles y documentos con citas.

¿Cómo supo la DINA dónde vivían los enlaces de Sergio Pérez ('Chico')? Misterio. Pero creemos que no fue él quien se los dijo porque murió en la tortura justamente por negarse a colaborar con sus interrogadores. De cualquier manera, la DINA se encuentra cada vez más cerca de Miguel Enríquez.

Pocos días después es detenida 'Sonia', un enlace de 'Jimena' (Carmen Castillo). 'Sonia', bajo amenaza de que sus hijos serían torturados, revela el lugar donde en un contacto de emergencia debe encontrarse con 'Jimena'. El punto queda en un paradero de micros (buses) cerca del Estadio Nacional.

Con esa información los hombres de la DINA preparan una emboscada para detener a 'Jimena' cuando concurra al lugar. Pero a ese punto no acude ella sino Miguel y Tito. Éstos van fuertemente armados, se produce un breve e intenso tiroteo; los miristas logran romper el cerco y escapar. Este episodio ocurre el viernes 4 de octubre, sólo un día antes del combate final. Ya la DINA está a menos de 24 horas de culminar con éxito la persecución.

¿Quién entregó la casa donde vivía Miguel Enríquez Espinosa? Ningún militante del MIR lo hizo. Si fue así, entonces ¿cómo dio la DINA con el lugar?

La ubicación exacta de la casa donde vivía el jefe del MIR no fue entregada por militantes del grupo, entre otros factores porque pocos la conocían. Sin embargo, en interrogatorios realizados, como ya hemos comentado, en medio de duras sesiones de tortura, algunos miembros entregan datos dispersos y fragmentarios que no tienen relación al ser analizados en forma parcelada, pero al estudiarlos en un contexto más amplio adquirieren un sentido. Por ejemplo, la DINA se entera de que 'Jimena' (Carmen Castillo) está embarazada, que se moviliza en un auto modelo renoleta, que la casa donde vive queda en la comuna de San Miguel; tal vez conocen también el color de la vivienda. Así, restringen el área de búsqueda a algunos kilómetros cuadrados en la zona sur de Santiago de Chile.

Pero nunca tuvieron la ubicación exacta. Porque, de lo contrario, ¿cómo se puede explicar que para iniciar la captura del dirigente clandestino más importante y peligroso, al que ellos suponen escoltado por varios hombres fuertemente armados, llegaran sólo dos vehículos con cuatro agentes? Si la jefatura de la DINA hubiese estado segura de que en ese lugar se encontraba Miguel Enríquez, habría tendido un cerco con cientos 
de hombres y ninguna de las cuatro personas que estaba en la vivienda habría tenido oportunidad de escapar ${ }^{58}$.

En síntesis, agentes de la DINA, analizando fragmentos de información obtenidos bajo tortura, consiguieron una ubicación relativa del refugio de Miguel Enríquez, pero nunca el lugar preciso.

A comienzos de octubre de 1974 los acontecimientos transcurren de prisa. El viernes 4 Miguel retorna a casa acompañado por José Bordas ('Coño Molina', probablemente, en ese entonces, responsable de la Fuerza Central $)^{59}$, para aumentar el poder de fuego ante la extrema peligrosidad del momento. Recordemos que ese mismo día Miguel y 'Tonio' tuvieron un enfrentamiento cerca del Estadio Nacional.

Esa noche son cuatro las personas que se alojan en la casa de calle Santa Fe: a Miguel y Catita se unen Tito y 'Coño Molina'. El día ha sido agitado y tenso; miran televisión hasta tarde.

El sábado 5 de octubre de 1974 comienza con normalidad. El barrio se ve tranquilo. Miguel y sus compañeros salen temprano a bordo del automóvil Fiat 125 blanco, para realizar labores habituales (contactos con sus enlaces, reuniones, chequeos) y Carmen Castillo se queda cocinando y ordenando el lugar, atenta a cualquier ruido producido en la calle.

Cerca de las 13 horas llegan los tres hombres. Al parecer, no han advertido que a cierta distancia son seguidos por una patrulla de la Policía de Investigaciones. Esos detectives creen que uno de los ocupantes del auto en que se moviliza Miguel y su gente es autor del reciente atraco al Banco de Chile ${ }^{60}$.

Los miristas rápidamente meten el coche al garaje y entran a la casa para buscar documentos y armas. A Catita le dicen que traiga sus cosas porque se van, ya que hay hombres de la DINA patrullando la calle. Ella se

\footnotetext{
${ }^{58}$ Ejemplo de lo que afirmamos fue la operación conocida como Fuenteovejuna. En efecto, la mañana del 7 de septiembre de 1983, un numeroso grupo de agentes divididos en varios pelotones cercaron el lugar, e instalaron un jepp equipado con una ametralladora punto 50 frente a la casa $\mathrm{N}^{\circ} 1330$ de calle Fuenteovejuna. La ametralladora dispara de inmediato y da muerte a Arturo Villabella ('Coño Aguilar'), miembro de la Comisión Política del MIR y jefe de todos los aparatos militares y sus guardaespaldas. Ninguno tuvo oportunidad de escapar. Véase, Pérez, Cristián: “Historia del MIR: 'Si Quieren Guerra, Guerra Tendrán...”,'p. 39.

${ }^{59}$ Sobre la Fuerza Central del MIR, véase Pérez, Cristián: "Historia del MIR: 'Si Quieren Guerra, Guerra Tendrán...”, 2003.

Creemos que la estructura militar del MIR estaba encabezada por Arturo Villabella (miembro de la Comisión Política y encargado de todas las estructuras militares); le seguía Mario Espinoza ('Juancho'), encargado nacional militar; Luis Carrasco ('Quila'), jefe de la Fuerza Central; y Aldo Flores ('Felipe'), segundo jefe de la Fuerza Central.

${ }^{60}$ Estos policías portan un retrato hablado de uno de los asaltantes del banco, el parecido con Miguel Enríquez es notable (véase crónica titulada "En Enfrentamiento con la Policía Muere el Prófugo Miguel Enríquez", diario La Tercera, domingo 6 de octubre de 1974, p. 42).
} 
encuentra lista para marcharse. Mientras preparan la salida, 'Tonio' vigila desde una ventana. "Vuelven a pasar", dice. Se refiere a agentes de la DINA y no a detectives, porque éstos, probablemente, esperando refuerzos aún no llegan al punto exacto.

Enseguida, cerca de la puerta principal se sienten ruidos que son provocados por el teniente Miguel Krassnoff Martchenko y un suboficial que se acercan para averiguar quiénes son las personas que viven ahí, ya que un niño les ha indicado esa casa; y también porque algunos vecinos les han dicho que durante toda la noche escriben a máquina; además, les han contado que uno de los hombres es inválido porque nunca se baja del auto en la calle. Hasta ese momento es todo lo que conocen aquellos agentes que se van acercando a la casa de Miguel Enríquez. Sospechas, sólo sospechas. No tienen la certeza de que el hombre que persiguen los observa desde una ventana y tiene un fusil y varias granadas en sus manos.

En el alto grado de tensión en que por esos días se encuentra el jefe del MIR, no resulta extraño que antes de comprobar exactamente quiénes son las personas que se acercan a la casa, o intentar alguna maniobra dilatoria, pasa el proyectil a la recámara de su fusil Avtomat Kalashnikov Karabin modelo AKS ${ }^{61}$, y "se apresura y les dispara"62. Entonces, fue el inconfundible sonido que emite esa arma al colocar una bala en posición de salida lo que puso en alerta a los agentes DINA. Efectivamente, al sentir ese ruido se arrojan al suelo, mientras la ráfaga pasa por arriba de sus cuerpos. Menos de un segundo es la diferencia que les permite conservar la vida.

Ésta fue la última oportunidad que tuvo Miguel Enríquez para escapar, ya que en minutos todo un dispositivo de cerco y aniquilamiento se activó en su contra. Al errar los disparos quedó sin opción para salir.

Mientras tanto, Catita toma la subametralladora Scorpio, corre hacia una ventana y también abre fuego. ¿Qué hacen 'Tonio' y 'Coño Molina'? ¿Disparan? José Bordas, desde la azotea dispara con un lanzacohetes soviético sobre el teniente oculto tras un poste, no consigue su objetivo

${ }^{61}$ El Avtomat Kalashnikov Karabin modelo AKS es la versión del fusil AKA-47 que utilizan paracaidistas y tropas acorazadas. A diferencia de éste, que tiene la culata de madera en posición fija, el diseño AKS la tiene de metal plegable y porta un kit con herramientas.

Tiene una longitud de $870 \mathrm{~mm}$; vacío y sin cargador pesa 3,4 kilos; el calibre es de $7.62 \mathrm{~mm}$; su alcance es de 800 metros; dispara hasta 600 tiros por minuto; la velocidad de salida de la bala es de 700 metros por segundo; y el cargador o depósito, que tiene forma curva, para no molestar al tirador cuando dispara desde el suelo, puede ser de 30 o 45 proyectiles. El AKA actualmente es el más famoso y respetado fusil automático del mundo. Es una de las pocas armas que han logrado convertirse en un símbolo cultural. Fue diseñado por Mikhail Kalashnikov en 1947 y entró en servicio en la fuerzas armadas soviéticas en 1949. Véase, www.kalashnikov.guns.ru

${ }^{62}$ Relato de Roberto Moreno (miembro de la Comisión Política del MIR). Entrevista con el autor (Santiago de Chile, junio de 1999). 
debido a que a corta distancia ese tipo de cohetes no alcanza a activarse; el proyectil destruye parte de la casa que esta detrás.

En minutos la vivienda $\mathrm{N}^{\circ} 725$ es un infierno. Astillas de vidrios y muebles se convierten en peligrosas esquirlas; se escucha el estallido de una granada y tableteo de fusiles y pistolas. Miguel continúa disparando, el AKS de culata plegable hierve entre sus manos, saltan vacíos los cargadores de treinta tiros. Está herido, un fino hilo de sangre corre por su mejilla, probablemente un rebote de bala le dio apenas comenzaba el combate. No se entregará.

De pronto Carmen Castillo recibe un tiro en su brazo. Se desmaya. Miguel Enríquez la pone en lugar seguro y continúa la lucha; poco después una bala atraviesa su rostro y pierde el conocimiento. ¿Ha muerto? 'Tonio', que es doctor en medicina se acerca para examinarlo. Al menos lo mira. Cree que ha muerto: "Comete un error médico"63. Este fallo es de enorme envergadura política, pero le permite conservar su vida, porque después de “examinar” a Miguel, 'Tonio' y 'Coño Molina' escapan del lugar. Saltan la pandereta posterior y llegan a la calle Varas Mena. Allí, a punta de fusiles, despojan de su Fiat 600 a una persona que pasaba por ahí. En ese auto arriban al paradero 20 de Santa Rosa. Luego se van a sus respectivos refugios. Han alcanzado a salir antes que el área sea sellada. Se van convencidos de que Miguel Enríquez, su jefe, ha muerto en el enfrentamiento.

Sin embargo, poco o mucho después, no sabemos exactamente cuánto tiempo pasó, Miguel recobra el conocimiento y sigue combatiendo, vuelve nuevamente a lanzar metralla el AKS. Miguel Enríquez no se rinde.

Ha pasado un tiempo largo desde que se inició la refriega, probablemente dos horas, el lugar ha sido rodeado por detectives, carabineros y agentes DINA; se hace imposible mantener la resistencia. Entonces Miguel Enríquez grita que no sigan disparando porque en la casa hay una mujer herida y embarazada. Luego trata de escapar hacia la calle San Francisco, salta el muro, cae en el patio de la casa signada con el $\mathrm{N}^{\circ} 5959$, al lado de una artesa, se afirma en ella tratando de protegerse. Algunos agentes, entre los que se encuentra una mujer, le cierran la única salida. Él les dice algo al mismo tiempo que descarga los últimos tiros de su fusil o de su revólver calibre 38 (no sabemos con certeza si fue fusil o revólver). Es un postrer intento por alcanzar la calle San Francisco y salir de la línea de fuego. La mujer agente dispara, luego lo hace el resto: diez proyectiles se estrellan contra su cuerpo. Deja de existir en el mismo lugar.

${ }^{63} \mathrm{La}$ expresión entre comillas es de Roberto Moreno (miembro de la Comisión Política del MIR). Entrevista con el autor (Santiago de Chile, junio de 1999). 
¿Fueron los disparos de la mujer los que acabaron con la vida de Miguel Enríquez? Es posible, no estamos seguros, la investigación queda abierta $^{64}$. La resistencia cesa. Por algunos momentos hay silencio.

Enseguida, un grupo de detectives penetra en la casa. En la primera pieza, tirada en el piso, inconsciente y en medio de un charco de sangre, yace Carmen Castillo ('Jimena'). Ya no representa un peligro; sin embargo, un hombre le da una patada en plena boca rompiéndole varios dientes. La trasladan al Hospital Militar. Es el último acto de una obra de la que ya se conocía el final. Ha concluido el enfrentamiento de Calle Santa Fe. La DINA ha muerto a su enemigo más enconado. ¿Se ha acabado el MIR?

En la vivienda encuentran armas, dinero y sistemas de impresión y falsificación de documentos. Es el golpe más duro contra la organización.

Esa noche el coronel Manuel Contreras, director de la DINA, con las armas aún humeantes ${ }^{65}$ y la satisfacción del deber cumplido, concurre hasta la capilla de la Escuela Militar para entregar a su hija en matrimonio.

Miguel Enríquez combatió durante dos horas solo contra fuerzas enormemente superiores. Su muerte en combate, igual que la de Che, lo convirtió en un ejemplo revolucionario. Como homenaje, en la ciudad de La Habana, un hospital lleva su nombre.

\section{El día después}

El MIR reaccionó con rapidez. El domingo 6 de octubre, en París, Edgardo Enríquez ('Simón') afirma que "la muerte de nuestro secretario general no significa de ninguna manera la liquidación del MIR. El fusil de Miguel ha caído, pero otro dirigente lo ha empuñado ya" ${ }^{66}$. Esta declaración pecaba de optimista, porque quien recogió el fusil no tenía —ni podía tener- el liderazgo de Miguel Enríquez. Después de la muerte del secretario general, la organización nunca pudo recobrar el vigor que su fallecido líder le había infundido. De todas maneras, los sobrevivientes continuaron la resistencia contra el gobierno militar. Hacia 1980 lograron constituir una nueva fuerza central profesionalizada, formada por cuadros político-militares que ingresaron clandestinamente al país como parte de la Operación Retorno. Al mando del dirigente histórico Arturo Villabella ('Coño Agui-

${ }^{64}$ Esta versión ha circulado entre los ex agentes de seguridad. En la actual etapa de la investigación no es posible comprobarla; la dejamos como una hipótesis en espera de obtener más antecedentes.

${ }^{65}$ Cavallo, Ascanio, Manuel Salazar y Óscar Sepúlveda: La Historia Oculta del Régimen Militar: Memoria de una Época, 1973-1988, 1999, p. 54.

${ }^{66}$ Diario La Segunda, lunes 7 de octubre de 1974. 
lar'), miembro de la Comisión Política y jefe militar de la organización, realizaron algunas acciones que causaron gran impacto entre la población. Después de siete años del combate de calle Santa Fe se volvió a hablar del MIR por un atentando contra el coronel Roger Vergara, director de la Escuela de Inteligencia del Ejército, y por el triple asalto de bancos en calle Santa Elena. Pero ninguna de estas acciones podía conducirlos al éxito. Su tiempo había pasado. El ocaso definitivo para el MIR fue el asesinato de Arturo Villabella y Hugo Ratier ('José'), sus jefes militares, en diciembre de $1983^{67}$.

Pero volvamos al 5 de octubre de 1974. 'Tito' ha escapado de la balacera y corre a su casa convencido de que Miguel Enríquez está muerto. $\mathrm{Al}$ otro día descubre que él lo ha abandonado cuando aún vivía. Se asila. Salva su vida y la de los suyos, pero el error médico que ha cometido será fuente de innumerables contratiempos más adelante, porque para el MIR, sobre todo para Edgardo Enríquez ('Simón'), hermano de Miguel, ese fallo es mucho más que un error médico. Desde Europa 'Tito' fue llamado a Cuba, allí sus compañeros en señal de reprobación no lo saludan. Se vio obligado a dejar la militancia para integrarse al Partido Comunista de Chile, colectividad que le ofreció apoyo en esos difíciles momentos.

Por su parte, en diciembre de 1974, 'Coño Molina', el otro militante que combatió junto a Miguel en la calle Santa Fe, cayó herido en un operativo montado por el Servicio de Inteligencia de la Fuerza Aérea (SIFA) en la intersección de las calles Alonso de Córdoba y Vitacura ${ }^{68}$. Fue trasladado a un hospital donde murió poco después. Con él también fue apresada su compañera.

Carmen Castillo estuvo casi todo el mes de octubre de 1974 internada en el Hospital Militar; allí era visitada frecuentemente por oficiales de la DINA, quienes le exigían entregar información sobre el paradero de Andrés Pascal Allende, el nuevo secretario general ${ }^{69}$. Por gestiones de su familia, ciertamente importante en Chile ${ }^{70}$, y de la Iglesia Católica, y por la enorme solidaridad que provocó en Europa la muerte en combate de su compañero,

${ }^{67}$ Véase Pérez, Cristián: "Historia del MIR: 'Si Quieren Guerra, Guerra Tendrán...”, 2003.

${ }^{68}$ Fue entregado a la SIFA por el 'Barba' Schneider.

${ }^{69}$ A los pocos días de muerto Miguel, Andrés Pascal asumió la dirección del MIR. Carmen Castillo relata que la DINA estaba tan cerca de la cúpula del grupo, que, encontrándose en el Hospital Militar, los agentes de seguridad le mostraron una carta manuscrita de Andrés Pascal Allende que habían interceptado, destinada a los otros miembros de la Dirección, donde comunicaba que él asumía el mando.

${ }^{70}$ El padre de Carmen Castillo E. (Catita o 'Jimena') es Fernando Castillo Velasco, ex rector de la Universidad Católica. Su tío Jaime Castillo Velasco, un importante abogado democratacristiano, posteriormente fue fundador de la Comisión Chilena de Derechos Humanos. 
fue expulsada del país. El hijo de Miguel que ella esperaba nació en Inglaterra enfermo de gravedad, porque le faltó oxígeno durante el enfrentamiento en que fue herida su progenitora; murió a los pocos días.

El teniente de Ejército adscrito a la DINA Miguel Krassnoff Martchenko, que encabezó el operativo y fue el primero en tirotearse con Miguel Enríquez, fue condecorado por esa acción. En 1974 recibió la medalla al valor militar. Ha sido el único soldado que ha obtenido ese estímulo desde la Guerra del Pacífico en 1879. Se retiró voluntariamente del Ejército en 1998.

Por su parte, la Dirección de Inteligencia Nacional siguió la implacable persecución contra el MIR, hasta prácticamente aniquilarlo en 1975. En efecto, el 15 de octubre de ese año se produjo un enfrentamiento en la parcela Santa Eugenia de Malloco entre los jefes del MIR y numerosos agentes de la DINA. En el tiroteo fue muerto Dagoberto Pérez (miembro de la Comisión Política); Andrés Pascal Allende (Secretario General) escapó del cerco y se asiló en la Embajada de Costa Rica; Nelson Gutiérrez (miembro de la Comisión Política) ${ }^{71}$ lo hizo en la Nunciatura; por su parte, Martín Hernández fue detenido en la casa de Gerardo Whelan ${ }^{72}$.

A comienzos del siglo XXI, algunos ex agentes de la DINA se encuentran detenidos y con numerosos procesos abiertos en su contra. Aún mantienen su lealtad con aquellos jefes que los guiaron en la cruzada contra las organizaciones político-militares de orientación marxista.

\section{TRES DÉCADAS MÁS TARDE}

Han transcurrido 30 años desde aquel sábado de primavera en que perdió la vida Miguel Enríquez. La guerra fría que dio legitimidad a la dictadura militar del general Augusto Pinochet, y a las organizaciones armadas que la combatieron, terminó con la caída de los muros en 1989. Ese hecho puso fin a la época de disparos y tortura en Chile. En 1990 asumió un gobierno democráticamente elegido, abriendo las puertas a otra etapa.

En este nuevo tiempo, nuestra sociedad ha revalorizado la democracia como un sistema esencial de la convivencia nacional, y como punto de partida en la búsqueda de una vida mejor para todos. Hemos descartado tanto la constitución de grupos armados para provocar cambios sociales, como la participación de integrantes de las Fuerzas Armadas en la aplica-

${ }^{71}$ Fue herido en ese enfrentamiento.

${ }^{72}$ Cavallo, Ascanio, Manuel Salazar y Óscar Sepúlveda: La Historia Oculta del Régimen Militar: Memoria de una Época, 1973-1988, p. 118. 
ción de torturas y otras violaciones a los derechos humanos. Este compromiso es el mejor homenaje para aquellos que en la época de disparos y tortura desaparecieron.

Por último, el MIR no es la fuerza político-militar de las décadas anteriores. Su pasado y el de Miguel Enríquez Espinosa no son más que la historia de aquellos jóvenes que entregaron su vida luchando con armas equivocadas por un objetivo justo: construir una sociedad mejor.

\section{REFERENCIAS}

Arancibia Clavel, Patricia, M. de los Ángeles Aylwin Ramírez, y Soledad Reyes del Villar: Los Hechos de Violencia en Chile: Del Discurso a la Acción. Santiago: Universidad Finis Terrae (Cidoc), Libertad y Desarrollo, 2003.

Arce, Luz: Viaje por el Infierno. Santiago: Editorial Planeta, 1993.

Avendaño, Daniel y Mauricio Palma: El Rebelde de la Burguesía: la Historia de Miguel Enríquez. Santiago: Ediciones Cesoc, 2001.

'Berrios, Sergio' (agente de la inteligencia naval argentina): Entrevista con el autor (Buenos Aires, abril, 2004.)

Camus, María Eugenia: "Las Confesiones de Schneider, 'El Barba'”. En Rocinante, $\mathrm{N}^{\circ}$ 49, noviembre de 2002.

Carvallo, Mauricio: "Miguel Krassnoff Martchenko. 'Comparto el 'nunca más' de Cheyre". En El Mercurio, domingo 6 de julio de 2003.

Castillo, Carmen: Un Día de Octubre en Santiago. Santiago: Editorial Sinfronteras, 1987.

Cavallo, Ascanio, Manuel Salazar y Óscar Sepúlveda: La Historia Oculta del Régimen Militar: Memoria de una Época, 1973-1988. Santiago: Grijalbo, 1997.

Comisión Nacional de Verdad y Reconciliación: "Informe de la Comisión Nacional de Verdad y Reconciliación”. Extra del diario La Nación, Santiago de Chile, 1991.

Comisión Política del MIR: "La Táctica del MIR en el Actual Período." [Diciembre 1973.] En Cecilia Radrigán y Miriam Ortega (eds.), Miguel Enríquez: Con Vista a la Esperanza. Santiago: Escaparate Ediciones, agosto de 1998.

Comisión Política del MIR: "A Fortalecer Nuestro Partido" [Santiago, 16 de junio de 1974]. En Cecilia Radrigán y Miriam Ortega (eds.), Miguel Enríquez: Con Vista a la Esperanza. Santiago: Escaparate Ediciones, agosto de 1998.

Contreras Sepúlveda, Manuel: La Verdad Histórica II. ¿Desaparecidos? Santiago: Ediciones Encina Ltda., septiembre 2001.

De la Fuente, Javier (dirigente del Partido Socialista en la clandestinidad): Entrevista con el autor (Putaendo, Chile, marzo de 1999).

Echeverría, Mónica y Carmen Castillo: Santiago-París. El Vuelo de la Memoria. Santiago: Lom Editores, 2002.

“El Mir Trasladó su Directiva a París”. Cable de la AP. La Segunda, 7 de octubre de 1974, p. 15.

"En Enfrentamiento con la Policía Muere el Prófugo Miguel Enríquez". La Tercera, domingo 6 de octubre de 1974, p. 42

Enríquez, Edgardo ('Simón'): "Conferencia de Prensa". Centro de Informaciones, Comité de Resistencia Antifascista. Documento N 19, La Habana, Cuba, 26 de junio de 1974. 
Farías, Víctor (ed.): La Izquierda Chilena (1969-1973): Documentos para el Estudio de su Línea Estratégica. Santiago: Centro de Estudios Públicos, 2000.

González Pino, Miguel y Arturo Fontaine Talavera (eds.): Los Mil Días de Allende. Centro de Estudios Públicos, 1997.

Guzmán, Nancy: Un Grito desde el Silencio. Detención, Asesinato y Desaparición de Bautista van Schouwen y Patricio Munita. Santiago: Lom Ediciones, 1998.

Iglesias, Juan Pablo: "Paul Aussaresses: 'En Chile se Aplicaron los Mismos Métodos que en la Guerra de Argelia"”. La Tercera, viernes 17 de octubre de 2003.

Kustcher Wach, Annie: "Los Contactos del MIR con la Fuerza Aérea". Ercilla, № 3105, 22 de febrero de 1999.

Moreno, Roberto (miembro de la Comisión Política del MIR): Entrevista con el autor (Santiago de Chile, junio de 1999).

Movimiento de Izquierda Revolucionaria (MIR-Chile): Resoluciones Pleno Extraordinario del Comité Central, enero 1984. Sin pie de imprenta.

Oficina del Alto Comisionado para los Derechos Humanos: "Convención contra la Tortura y Otros Tratos o Penas Crueles, Inhumanos o Degradantes". http://www.unhchr.ch/ spanish/html/menu3/b/h_cat39_sp.htm

Pascal Allende, Andrés (Secretario General del MIR): Entrevista con el autor (La Habana, agosto de 1999).

Pérez, Cristián: "Salvador Allende, Apuntes sobre su Dispositivo de Seguridad: El Grupo de Amigos Personales (GAP)". En Estudios Públicos, N 79, invierno, 2000.

Pérez, Cristián: "Historia del MIR: 'Si Quieren Guerra, Guerra Tendrán...'”. En Estudios Públicos, $\mathrm{N}^{\circ}$ 91, invierno, 2003.

Quiroga, Patricio: Compañeros. El GAP: La Escolta de Allende. Santiago: Aguilar, 2001.

Rivas, Patricio (miembro del Comité Central del MIR): Entrevista con el autor (Santiago de Chile, junio de 1999).

Robin, Marie-Monique: Escuadrones de la Muerte. La Escuela Francesa. Video documental, París, 2003.

Tamayo, Tania y Claudia Lagos: "Arquitectura del Espanto: Casas de Tortura y Centros de Detención”. En Rocinante, $\mathrm{N}^{\circ}$ 57, julio de 2003.

Toro, Víctor (miembro del Comité Central del MIR): Entrevista con el autor (Nueva York, abril de 1999).

Zalaquet, Cherie: "Manuel Contreras: 'Pinochet nos Dejó Absolutamente Solos"”. En Revista del Sábado de El Mercurio, sábado 11 de septiembre de 2004.

www.kalashnikov.guns.ru 